\section{Head injuries in the elderly}

SIR,-We welcomed Mr S Galbraith's clear account of the importance of head injury in the elderly ( 7 February, p 325). In a recent survey we compared 1571 patients aged under 65 admitted to our head and spinal injury unit in one year with 449 patients aged 65 years or over admitted during two one year periods.' Intracranial haematomas were more than three times more common in those aged over 65 than in those under 65 , with an overall incidence of $9 \cdot 4 \%$ in the older group and $2 \cdot 7 \%$ in the younger group. The differences were even more pronounced when severity of injury was considered using the criteria of the Glasgow coma scale; many of the elderly victims of head injury who were classified as having mild or moderate injuries had intracranial haematomas. This supports the need for access to neuroradiological facilities and particularly computed tomography. The mortality after admission was $7 \%$ in the older group, compared with $2 \%$ in the younger group. Although those aged 65 years or over constituted $15 \%$ of all admissions to our unit, they accounted for $10 \%$ of patients with head injuries admitted to Scottish hospitals in 1981 and 83 had a mean stay of $8 \cdot 8$ days, compared with $2 \cdot 7$ days for those under 65 years.

The elderly thus represent a significant proportion of all cases of head injury, with a high morbidity and mortality. They require careful monitoring and observation with access to computed tomography and neurosurgical skill when necessary.

Brian Pentland

Astley Ainslie Hospital Christopher W ROY

Edinburgh EH9 2

Head and Spinal Injuries Unit,

Royal Infirmary,

Edinburgh EH3 9YW

1 Pentland B, Jones PA, Roy CW, Miller JD. Head injury in the elderly. Age Ageing 1986;15: 193-202.

SIR,-Having just completed a prospective study of 56 patients aged over 65 who were admitted over six months with head injuries to the head and spinal injury unit in Edinburgh, we were interested to read Mr S Galbraith's leading article (7 February, p 325). Of the 56 patients in our study, nine had suffered moderate or severe head injury, eight dying as a result. The 48 survivors, 47 of whom had sustained only minor head injuries, were seen six weeks after discharge. Thirty nine had returned to the place where they were living before they suffered the head injury. Eight, however, required home help (or more help if they were already receiving it), seven had to be visited by a district nurse, and 17 received increased visits from relatives. Four of those who had changed their address had moved to stay with relatives. The remainder were in a geriatric assessment ward (two) or a registered nursing home (one) or were receiving long stay psychogeriatric care (one). The mean length of stay in the ward was 6.8 days. It therefore seems that minor head injury in the elderly, although it does not often result in long term admission to hospital, necessitates increased community support.

We also carried out simple screening investigations (chest radiography, electrocardiography, measurement of urea and electrolyte concentrations, and full blood count) to detect medical disorders that might have contributed to or been masked by the head injury. Of the 48 patients thus screened, 27 had abnormalities, mainly minor and non-specific. In only three cases of minor head injury $(7 \cdot 3 \%$ of those screened) did the results alter the management of the patient. One patient had left ventricular failure, and two had iron deficiency anaemia. In no cases of moderate or severe head injury did screening show an underlying medical cause for the head injury. Frailty and reduced functional reserve, rather than specific medical disorders detectable by the screening used, seemed to have made these elderly patients susceptible to the more serious consequences of head injury.

Geriatricians already have a role in the care of elderly trauma patients in orthopaedic units. ${ }^{12}$ Perhaps there is now a case for establishing similar links between geriatricians and neurosurgeons.

J A WILSON C T CURRIE

Department of Geriatric Medicine,

City Hospital,

Edinburgh EH $105 S$

1 Boyd RV, Hawthorne J, Wallace WA, Worleck PH, Compton GW. The Nottingham orthogeriatric unit after 1000 admissions. Injury 1983;15:193-6.

2 Burley LE, Scorgie RE, Currie CT, Smith RG, Williamson J. The joint geriatric orthopaedic service in south Edinburgh: November 1979-October 1980. Health Bulletin 1984;42: 133-40.

SIR,-Mr S Galbraith (7 February, p 325) emphasised that elderly patients with head injuries should be managed differently from younger patients and pointed out the importance of "stroke" and "confusion" as presenting signs of intracranial injury. Mr Gordon Brocklehurst and coworkers (7 February, p 345) did not make this point and, although they reported subdural haematoma as the most common of the intracranial haematomas, they did not relate this to the time of injury or age. Nor did they comment on the proportion of patients with minor head injury who developed subdural haematomas.

Subdural haematomas presenting with localising neurological signs are not uncommon in geriatric practice, though lesions that occupy intracerebral space may mimic them. For example, at this hospital recently a patient with a four and a half month history of intermittent disorientation after falling backwards off a stool was found to have a midline tumour, probably a meningioma. In one year there were five cases of subdural haematoma in patients aged 74-88 among 190 unselected admissions to our geriatric unit. Three patients presented with localising neurological signs and two with drowsiness, one of whom died before diagnosis. Two patients in the first group became disorientated. Four patients underwent surgical drainage and, having recovered well, were discharged home.

It is essential that neurosurgical units do not use criteria to assess the elderly that increase the likelihood of missing an eminently treatable lesion. ${ }^{1}$ In a study reported from Nottingham seven out of eight patients aged 49-60 were diagnosed as having such lesions while alive, whereas seven out of 13 aged 61-81 were diagnosed as having lesions only at necropsy. ${ }^{2}$

Department of Geriatric Medicine

O M P JOLOBE Tameside General Hospital,

Lancashire OL7 6RB

Selly Oak Hospital

Birmingham B29 6JF

P P MAYER

Noltie K, Denham MJ. Subdural haematoma in the elderly. Age Ageing 1981;10:241-6.

2 Dronfield MW, Mead GM, Langman MJS. Survival and death from subdural haematoma on medical wards. Postgrad Med $\mathcal{F}$ $1977 ; 53: 57-60$
Snoring as a risk factor for ischaemic heart disease and stroke in men

SIR,-Dr P Yates (7 February, p 371) suggested that polycythaemia is an important factor explain ing the increased cardiovascular morbidity in snorers. His point is undoubtedly relevant.

Patients with sleep apnoea syndrome may develop secondary polycythaemia, ${ }^{12}$ but it is not common. We have not found any report that patients with sleep apnoea generally have polycythaemic haemoglobin concentrations; for example, Shepard et al reported a mean value (SD) of $153(15) \mathrm{g} / 1 .{ }^{3}$ We have had the same experience in our patients.

As the prevalence of obstructive sleep apnoea seems to be $1-2 \%$ in middle aged men and only a few of these patients develop polycythaemia, it is unlikely that this small subgroup could explain the overall increase in the risk of cardiovascular disease in snorers. In a small subgroup of patients with apnoea polycythaemia might increase the cardiovascular risk. On the other hand, the role of local vasoconstriction related to hypoxaemia and in creased blood viscosity (even with normal values of packed cell volume) in sleep apnoea might perhap be more important. There is, however, no evidence on that score. Therefore, we concluded that the increased risk in snorers was best explained by the short term effects of sleep apnoea: hypoxaemia and its consequences-for example, susceptibility to cardiac arrhythmias. The second best explanation is the higher prevalence of hypertension among snorers. Other possible mechanisms are not well documented. Certainly, we agree that enhanced coagulation or decreased fibrinolysis demands more research.

M KosKenvuo J KAPRIO K HEIKKILÄ S SARNA

Department of Public Health,

Ullanlinna Sleep Disorders Clinic,

T TELAKIVI M PARTINEN

Department of Neurology,

University of Helsinki

Helsinki 29,

Finland

1 Neil JF, Reynolds CF, Spiker DG, Kupfer DJ. Polycythaemia vera and central sleep apnoea. Br Med f 1980;280:19.

2 Bradley TD, Phillipson EA. Pathogenesis and pathophysiology of the obstructive sleep apnoea syndrome. Med Clin North Am 1985;69:1169-85.

3 Shepard JW, Garrison MW, Grither DA, Dolan GF. Relationship of ventricular ectopy to oxyhemoglobin desaturation in patients with obstructive slep apnoea. Chest 1985;88:335-40.

Christ Church conference on postgraduate education-25 years on

SIR,-Dr Alex Paton (14 February, p 393) rightly highlights the confusion currently besetting postgraduate medical education. I am a clinica tutor nearing the end of my tutorship in a smal health district. The past six years have been most enjoyable, but I am very conscious of the inadequacies of my tenure. In Wessex the newly appointed tutor has the advantage of a strong regional structure in postgraduate medical education. Tutors meet regularly in the regional centre and once a year attend a two day residential meeting. Thus the enthusiastic innocent is guided into a job for which he or she is singularly unprepared. The tutor relies heavily on his centre administrator, and even with this help he is unlikely to feel that he is getting to grips with his responsibilities, all of which he has to fit into his spare time until he has been in the post for a year or two. These include programme organising, study 